\title{
1 Mechanics of Cocoon Secretion in a Segmented Worm
}

2 (Annelida: Hirudinidae)

$5{ }^{1}$ Anthony M. Rossi, William M. Saidel, Christopher J. Gravante, Charlene W.

6 Sayers, *Daniel H. Shain

8 Biology Department, Rutgers The State University of New Jersey, 315 Penn St.,

9 Camden, NJ 08102

10

$11{ }^{1}$ Current address: Department of Biology, New York University, 100 Washington

12 Square East, New York, NY 10003

13

14

15

16

17

18 *corresponding author

19 dshain@camden.rutgers.edu

20

21

22

23

24

25

26

27

28

29

30

31 


\section{Abstract}

33 Clitellate annelids (e.g., segmented earthworms, leeches) secrete proteinaceous

34 cocoons into which eggs are deposited. The process of cocoon production is

35 characterized by the coordinated release of micro-granules from secretory cells

36 positioned asymmetrically within the clitellum. Collectively, these assemble into a

37 tubular cocoon sheath that is sealed at either end by globular opercula. By

38 transmission electron microscopy (TEM), we show here that granules destined to

39 the cocoon operculum in the leech, Erpodbdella obscura, display a series of

40 concentric rings surrounding a structureless core with dimensions approximating

41 a single nanoglobule found in the operculum. Upon their channeling to the

42 surface through narrow tubules, granules are secreted into the cocoon lumen

43 where they appear to fragment upon contact with the operculum matrix. The

44 distribution of partial concentric ring structures throughout the operculum

45 suggests that granular fusion causes dynamic fragmentation of outer surface

46 material, which thereafter integrates into operculum nanoglobules and cavities.

47 Other granules within the same secretory cell display a punctate pattern and

48 likely fuse with the cocoon sheath prior to crystallization.

49

50 Keywords: clitellate, reproduction, biomaterial, egg case, operculum, granule 


\section{1. Introduction}

52 Clitellate annelids (e.g., earthworms, leeches) secrete egg sacs, or cocoons,

53 from specialized midbody segments known as the clitellum. This process is

54 characterized by formation of a cocoon sheath/wall that initially surrounds the

55 clitellum and into which nutritive cocoon fluid and eggs are deposited. Thereafter,

56 the cocoon sheath is passed over the worm's head while it is concomitantly

57 sealed at both ends by glue-like plugs, called opercula (Hirao 1965; Wilkialis

58 1975). In a few leech species (e.g., Haementeria ghilianii; Helobdella

59 papillornata), cocoons are secreted as a sac encircling the ventral gonopores,

60 and are sealed with a single operculum. The completed cocoon is deposited onto

61 the substratum (or sometimes on the venter of leeches) where it serves as

62 protective barrier and microenvironment for embryonic development.

63 Clitellate worms secrete various cocoon types depending on constraints

64 imposed by environmental pressures and developmental strategies (e.g.,

65 oviparous vs. albuminotrophy; Sawyer 1984). For example, mechanically strong,

66 hard-shelled cocoons are abandoned by the parent worm, leaving embryos to

67 develop independently on nutritive cocoon fluid (albuminotrophy), while large,

68 yolky (oviparous) eggs are typically deposited into membranous or gelatinous

69 cocoons that are often brooded by parent leeches (Davies and Oosthuizen 1992;

70 Govedich 2004; Siddall et al. 2005). In an unusual display of parental care,

71 species of Theromyzon cement membranous cocoons to their venter, and upon

72 hatching bring juveniles to their first blood meal, a duck nare (Wilkialis and

73 Davies 1980).

74 Despite very different cocoon types that accommodate various life cycle

75 requirements, all Clitellata appear to build cocoons by the coordinated release of

76 proteinaceous micro-granules that are synthesized within the clitellum. The

77 process of granule synthesis and secretion has been examined in a few clitellate

78 species (e.g., Branchiobdella pentodonta, Eisenia foetida, Enchytraeus

79 fragmentosus, Lumbricillus rivalis, Tubifex hattal), leading to the identification of

80 distinct granule types that contribute material to the cocoon wall and opercula,

81 respectively (Hirao 1965; Farnesi and Vagnetti 1973; Hess and Vena 1974; 
82 Richards 1977; Suzutani-Shiota 1980; Morris 1983). The ultrastructure of the

83 cocoon wall is characterized by stacked, fibrous layers that, when sectioned

84 obliquely, display Bouligand-like patterns with varying step-angles (Knight and

85 Hunt 1974; Dimitriu and Shain 2004; Marotta et al. 2007). In contrast, opercula

86 display random, porous arrays of spherical nanoglobules with no obvious

87 ultrastructural organization (Rossi et al. 2013). Fully constructed cocoon wall and

88 operculum biomaterials display extraordinary physical properties, including

89 mechanical strength and thermal/chemical resilience (Mason et al. 2004;

90 Coleman et al. 2008).

91 The process by which clitellar micro-granules segregate and assemble

92 into the cocoon wall and operculum, respectively, remains enigmatic. Clearly, the

93 material components of the cocoon are contained within granules, but

94 intermediate steps progressing from granule synthesis to the apparent fusion of

95 granules and self-assembly of cocoon structures, remains mostly unexplored.

96 Here, we approached this question by sectioning through specimens of the

97 leech, Erpobdella obscura, in the process of secreting a hard-shelled cocoon. An

98 unexpected morphological structure, namely electron dense concentric rings,

99 targeted a set of granules as operculum-bound. The scattered remnants of these

100 structures suggest that outer layers of the granule fragment upon contact with

101 existing cocoon material and integrate into the operculum matrix, while the inner

102 core is released as a single nanoglobular particle.

103

104 2. Materials and Methods

105 2.1. Specimens

106 Erpobdella obscura specimens were collected from Haddon Lake, $\mathrm{NJ}$, and

107 Theromyzon tessulatum specimens were from Golden Gate Park, CA. Individuals

108 were maintained in glass bowls in $0.3 \%$ Instant Ocean, as described (Mason et

109 al. 2005).

110

111 2.2. Histology 
112 Specimens were processed for histological sections according to Sayers et al.

113 (2009). Briefly, leeches were fixed in 10\% formaldehyde, dehydrated in an

114 ascending ethanol series to xylene, embedded in Paraplast Extra ${ }^{\circledR}$ and sectioned

115 at 3-4 $\mu \mathrm{m}$. Sections mounted on glass slides were stained with Masson's

116 trichrome (Sheehan and Hrapchak 1980). Images were captured with a Canon

117 Rebel XT camera coupled with a Zeis Universal microscope using a PI $232 \mathrm{~mm}$

11828 adaptor (Perspective Image LLC, Beaverton, OR).

\subsection{Scanning Electron Microscopy}

121 Cocoons were fixed in $70 \%$ ethanol and selected under a stereomicroscope for

122 visible and protruding opercula. After ethanol series dehydration, cocoons were

123 critically-point dried with $\mathrm{CO}_{2}$ before manual fracturing into equal halves or

124 complete operculum removal to expose interior operculum and cocoon wall

125 surface ultrastructure. Cocoon pieces were then mounted with carbon tape on

126 aluminum studs, sputter coated with gold/palladium and imaged with a

127 LEO1450EP scanning electron microscope.

\subsection{Transmission Electron Microscopy}

130 Specimens were fixed overnight in a buffered aldehyde fixative (2.5\%

131 paraformaldehyde, $2 \%$ gluteraldehyde, $0.1 \mathrm{M}$ sodium cacodylate, $\mathrm{pH} 7.2)$ for $2 \mathrm{~h}$

132 at $4^{\circ} \mathrm{C}$, washed in $0.1 \mathrm{M}$ sodium cacodylate buffer $(\mathrm{pH} 7.2)$ and post fixed in $1 \%$

133 osmium tetroxide. To enhance image contrast, tissues were pre-stained with $2 \%$

134 uranyl acetate for $2 \mathrm{~h}$ at $4^{\circ} \mathrm{C}$ prior to ethanol dehydration and propylene oxide

135 solvent transition. After solvent infiltration with ascending concentrations of

136 Spurr's resin, tissue was embedded in pure Spurr's resin for $4 \mathrm{~h}$ at room

137 temperature and then cured in plastic molds with fresh Spurr's resin at $60^{\circ} \mathrm{C}$ for

$13848 \mathrm{~h}$. Ultrathin sections were made with an LKB ultramicrotome fitted with a

139 diamond knife, collected on 100 and 200 mesh grids, and viewed in a Zeiss EM

140902 electron microscope at $50 \mathrm{kV}$ equipped with electron energy loss

141 spectroscopy (EELS). 


\section{3. Results}

144 A fully assembled, hard-shelled cocoon secreted by the leech, Erpodbdella

145 obscura is shown in Figure 1. Histological cross-sections within the clitellum of a

146 mature parent leech in the process of egg laying revealed the presence of

147 abundant granule-secreting cells with associated, granule-filled tubules (Fig. 2).

148 To examine ultrastructural features within the cocoon-associated micro-granules

149 targeted for secretion, we cut through corresponding clitellar segments in cross-

150 section and examined by TEM. Sacs of granules were identified in the cell body

151 that displayed a series of electron dense, concentric rings (electron dense

152 lamellae-EDL) surrounding a structureless core; within the same region, other

153 granules lacked rings and displayed distinct punctate patterns (Figs. 3, 4). Both

154 types of granules were grouped in sacs containing 5-10 granules, respectively

155 (Fig. 3). The relatively narrow width of tubules extending to the body surface

156 appeared to restrict granule flow to 1-2 at a time (Fig. 5).

157 The release of granules into the cocoon lumen followed by their putative

158 fusion with existing cocoon wall material and subsequent crystallization was

159 captured in a different species, Theromyzon tessulatum (Fig. 6). The

160 presumptive fusion of operculum-bound granules in E. obscura led to fragments

161 of EDL appearing within, surrounding and spanning cavities of the operculum

162 matrix (Fig. 7). These fragments acquired random shapes and contained variable

163 layers, but their dimensions were consistent with EDL observed within granules

164 of the cell body and tubules (cf. Figs. 4-7). Note that electron-dense shards (e.g.,

165 Fig. 7) appear to be a component of the operculum matrix, as described

166 previously (Rossi et al. 2013).

$167 \quad$ Fully formed operculum material was characterized by clusters of

168 associated nanoglobules with dimensions ranging from 50-300 nm (Fig. 8; Rossi

169 et al. 2013), while the ultrastructure of the cocoon sheath displayed fibrous and

170 punctate (cross sections) patterns reminiscent of granules observed in the cell

171 body (cf. Figs. 4B, 8B). Using approximate dimensions of granules and the

172 assembled cocoon, we estimate that $1-2 \times 10^{7}$ granules of each type were

173 required to construct a single E. obscura cocoon (cocoon sheath + opercula). 


\section{4. Discussion}

176 Employing the leech, Erpobdella obscura, as a representative subject, we

177 identified two distinct granule types within clitellar tissue that likely contribute

178 material to the cocoon sheath/wall and opercula, respectively. The occurrence of

179 both granule types proximal to each other (i.e., within the same cell body; see

180 Fig. 3) was reported within Type C clitellar cells of Tubifex hattai (i.e.,

181 azocarmine- and aniline blue-staining, respectively; Hirao 1965), but differs from

182 that observed in the leech Theromyzon tessulatum, in which cocoon wall- and

183 operculum-bound granules are partitioned into regionally separated cell types

184 (i.e., Type II/III cells; Sayers et al. 2009). Likewise, clitellar secretory cells in other

185 species (e.g., in Tubifex hattai, Enchytraeus fragmentosus, Lumbricuillus rivalis)

186 typically contain only one granule type and are asymmetrically positioned in the

187 clitellum (e.g., Hess and Vena 1974; Richards 1977; Suzutani 1977; Suzutani-

188 Shiota 1980). In contrast, clitellum granules identified in the giant Amazonian

189 earthworm, Rhinodrillus priolii, appear to contain both cocoon wall and

190 operculum material within the same granule (Lang et al. 2012). Thus,

191 considerable variation in granular content appears to be tolerated across species

192 types. Aside from some positional asymmetry within the clitellum, however, the

193 mechanism by which cocoon wall or operculum material segregates to its

194 structural target in any species remains unclear.

195 In E. obscura, a previously undescribed structure--namely a series of

196 electron dense concentric rings (EDL)--marks these granules as operculum-

197 bound based on EDL fragments found in the assembled operculum (cf. Figs. 3,

198 6). The central core of these granules comprise a structureless sphere with

199 dimensions comparable with that of nanoglobules $(\sim 100-200 \mathrm{~nm})$ that associate

200 to form opercula (see Fig. 8A; Rossi et al. 2013). Thus each granule appears to

201 contribute a single nanoglobule to the mature operculum, requiring $\sim 10^{7}$ granules

202 in total. The randomly scattered fragments of EDL within operculum

203 nanoglobules and cavities suggest that outer layers of operculum-bound

204 granules fragment upon fusion with other granules (or operculum material), thus 
205 releasing the internalized nanoglobule which thereafter associates with the 206 operculum matrix. In some cases, EDL fragments associate permanently with

207 free nanoglobules and become structural components of the operculum.

208 The composition of EDL remain unknown. Previous studies suggest that

209 the cocoon wall and opercula are built from the same protein in T. tessulatum

210 (Tcp; Mason et al. 2004); specifically, a glycosylated form of Tcp exists as a

211 monomer and contributes to nanoglobules that comprise opercula, while de-

212 glycosylated Tcp proteins assemble into polymers that characterize the fibrous

213 cocoon wall (Mason et al. 2005; Sayers et al. 2009). Possibly, EDL in E. obscura

214 represent polymeric fibers surrounding a glycosylated, structureless core, and

215 upon fusion EDL fragments integrate into both opercula and the cocoon wall (the

216 latter of which cannot be distinguished from other fibrous material). Indeed, EDLs

217 display some resemblance to spiral "fingerprint" patterns in cocoon wall-bound

218 granules of T. hattai (Suzutani 1977; Suzutani-Shiota 1980). Alternatively, EDL

219 may be the remains of Golgi lamellae from which the structureless core

220 (nanoglobule) is synthesized, though the energetic requirements for encircling all

$221 \sim 10^{7}$ nanoglobules with Golgi layers would likely be prohibitive to operculum

222 production.

223 Granules likely destined to the cocoon wall in E. obscura have a pocked

224 appearance similar to that observed in Branchiobdella pentodonta, Lumbricillus

225 rivalis and Eisenia foetida, which are thought to be in a paracrystalline state

226 (Farnesi and Vagnetti 1973; Richards 1977; Morris 1983). The spatial

227 organization of electron dense material within some of these $E$. obscura granules

228 (e.g., see Fig. 4B) suggests an early stage of polymerization, since no distinct

229 fibrous patterns were observed despite their random orientations in TEM sections

230 (i.e., polymerized material would appear pocked in cross-section, but fibrous if

231 rotated in any other direction). Regardless of the species, granular material is

232 likely to be in paracrystalline form prior to fusion with existing cocoon wall

233 material to facilitate its integration into the fibrous matrix. Indeed, polymerization

234 and cocoon hardening appears to be delayed in E. obscura (and T. tessulatum; 
235 see Fig. 6) until after granular fusion, which may allow time for the parent leech

236 to physically shape the cocoon into its mature form (Brumpt 1900).

\section{5. Conclusion}

239 The detailed examination of related cocoon types (e.g., gelatinous, membranous,

240 hard-shelled) in the context of granular content and progression through the

241 secretory process will be necessary to resolve the different morphologies and

242 strategies of cocoon production among diverse clitellates (and possibly their

243 ancestral, tube-dwelling polychaetes). From analyses to date, however, it seems

244 clear that the major structural components of the cocoon are built by the timely

245 production and coordinated secretion of distinct micro-granule types (up to $\sim 4 \mathrm{x}$

$24610^{7}$ granules in total per E. obscura cocoon), which then segregate and self-

247 assemble into the fibrous cocoon wall and nanoglobular opercula.

\section{Acknowledgments}

253 Supported by NSF grant DBI-0216233 to DHS. 


\section{References}

256 Bouligand $Y$ (1972) Twisted fibrous arrangements in biological materials and

257 cholesteric mesophases. Tissue \& Cell 4, 189-217.

259 Brumpt E (1900) Reproduction des Hirudinées. Mem. Soc. Zool. Fr. 13, 286-430.

261 Coleman J, Marotta R, Shain DH (2008) Surface topology and structural integrity

262 of the Theromyzon tessulatum (Annelida:Hirudinea:Glossiphoniidae) cocoon. J.

263 Morphol. 269, 812-819.

265 Davies RW (1984) Sanguivory in leeches and its effects on growth, survivorship 266 and reproduction of Theromyzon rude. J. Can. Zool. 62, 589-593.

268 Dimitriu C and Shain DH (2004) Ultrastructural properties of the Theromyzon

269 (Annelida: Hirudinea) cocoon membrane. Micron 35, 281-285.

271 Hess RT and Vena JA (1974) Fine structure of the clitellum of the annelid

272 Enchytraeus fragmentosus. Tissue and Cell 5, 503-514.

274 Hirao Y (1965) Cocoon formation in Tubifex, with its relation to the activity of the 275 clitellar epithelium. J. Fac. Sci. Hokkaido Univ. Ser. VI Zool. 15, 625-632.

277 Knight DP and Hunt S (1974) Molecular and ultrastructural characterization of the 278 egg capsule of the leech Erpopdella octoculata L. Comp. Biochem. Physiol. 47A, 279 871-880.

281 Lang SA, Garcia, MV, James SW, Sayers CW, Shain DH (2012) Phylogeny and

282 Clitellar Morphology of the Giant Amazonian Earthworm, Rhinodrilus priollii

283 (Oligochaeta: Glossoscolecidae). American Midland Naturalist 167, 384-395. 
285 Marotta R, Shain DH (2007) Irregular helicoids in leech cocoon membranes. J.

286 Struct. Biol. 158, 336-343.

288 Mason TA, Mcllroy PJ and Shain DH (2004) A cysteine-rich protein in the

289 Theromyzon (Annelida: Hirudinea) cocoon membrane. FEBS Lett. 561, 167-172.

291 Mason TA, Paulson TL and Shain DH (2005) Cocoon deposition and hatching in

292 the aquatic leech, Theromyzon tessulatum. American Midland Naturalist 154, 293 78-87.

295 Mason TA, Mcllroy PJ and Shain DH (2006) Structural model of an

296 antistasin/notch-like fusion protein in the cocoon wall of the aquatic leech,

297 Theromyzon tessulatum. Journal of Molecular Modeling 12, 829-834.

299 Morris GM (1983) The cocoon-producing cells of Eisenia foetida (Annelida,

300 Oligochaeta): a histochemical and ultrastructural study. J. Morphol. 177, 41-50.

302 Richards KS (1977) The histochemistry and ultrastructure of the clitellum of the

303 enchytraeid Lumbricillus rivalis (Oligochaeta: Annelida). J. Zool., London 183, 304 161-176.

306 Rossi A, Saidel WM, Marotta R, Saglam N, Shain DH (2013) Operculum

307 ultrastructure in leech cocoons. J. Morphol. 274, 940-946.

309 Sayers CW, Coleman J, Shain DH (2009) Cell dynamics during cocoon secretion

310 in the aquatic leech, Theromyzon tessulatum (Annelida: Clitellata:

311 Glossiphoniidae). Tissue and Cell 41:35-42.

313 Sawyer RT (1984) Arthropodization in the Hirundinea; evidence for a

314 phylogenetic link with insects and other Uniramia. Zool. J. Linn. Soc. 80, 303-

315322. 
317 Sheehan D, Hrapchak B (1980) Theory and Practice of Histology. C.V. Mosby

318 Co., St. Louis, Ml.

319

320 Suzutani C (1977) Light and electron microscopical observations on the clitellar

321 epithelium of Tubifex. J. Fac. Sci. Hokkaido Univ. Ser. VI Zool. 21, 1-11.

322

323 Suzutani-Shiota C (1980) Ultrastructural study of cocoon formation in the

324 freshwater oligochaete, Tubifex hattai. J. Morphol. 164, 25-38.

325

326 Wilkialis J and Davies RW (1980) The reproductive biology of Theromyzon

327 tessulatum (Glossiphoniidae: Hirudinoidea), with comments on Theromzyon

328 rude. J. Zool., London. 192: 421-429.

329 


\section{Figure legends}

331 Figure 1. Fully assembled cocoon from the leech, Erpobdella obscura. The

332 cocoon wall (CW) forms a tube that is sealed at either end by opercula (arrows).

333 Scale bar $500 \mu \mathrm{m}$. Insert shows an outwardly protruding operculum. Scale bar

$334100 \mu \mathrm{m}$.

335

336 Figure 2. Histological cross-sections through the clitellum of an Erpobdella

337 obscura parent leech in the process of cocoon secretion. A) Clitellar tissue (CT)

338 containing secretory granule cells was observed between the gut (g) and external

339 cuticle (arrowhead). Scale bar $100 \mu \mathrm{m}$. B) Granule cells (Gc) were abundant

340 within the CT. Scale bar $40 \mu \mathrm{m}$. C) Gc and tubules (Tu) were observed

341 throughout the CT. Scale bar $10 \mu \mathrm{m}$. D) Granules were apparent within Gc and

342 Tu. Scale bar $4 \mu \mathrm{m}$.

344 Figure 3. Granules within a clitellar secretory cell. Operculum-bound (star) and

345 cocoon wall-bound (diamond) granules were in sacs (arrows) containing 5-10

346 granules per sac. Scale bar $100 \mathrm{~nm}$.

348 Figure 4. Distinct granule types within the clitellum of Erpobdella obscura. A)

349 Operculum-bound granules displayed electron dense lamellae (EDL) surrounding

350 a structureless core with dimensions comparable with mature nanoglobules $(\mathrm{Ng})$

351 found in opercula. B) Cocoon wall-bound granules (diamond) displayed

352 organized, punctate patterns. Scale bars $100 \mathrm{~nm}$.

353

354 Figure 5. Operculum-bound granules (star) in a narrow tubule. Between 1-2

355 granules were channeled to the epidermal surface by tubules. Adjacent cocoon

356 wall-bound granules (diamond) are shown. Scale bar $100 \mathrm{~nm}$.

358 Figure 6. Interactions of granules with existing cocoon material in Theromyzon

359 tessulatum. A) Putative fusion of a granule with the cocoon wall; arrow identifies 
360 the interface site. B) Regions of paracrystalization are adjacent to polymerized, 361 fibrous material (arrows). Scale bars $100 \mathrm{~nm}$.

362

363 Figure 7. Fragments of electron dense lamellae (EDL) integrated into the 364 operculum matrix (OM). EDL fragments (arrows) partially filled (A, B) and/or 365 spanned (B) cavities (c), lined cavities (A, B), appeared on surface OM (C) or 366 were embedded with the OM (D). Scale bars $100 \mathrm{~nm}$. Electron-dense shards 367 observed in some panels have been described previously (Rossi et al. 2013). 368

369 Figure 8. Ultrastructure of major Erpobdella obscura cocoon components. A)

370 Nanoglobules comprising operculum material. Arrow identifies a single

371 nanoglobule; c - cavity. Scale bar $500 \mathrm{~nm}$. B) Dashed line separates adjacent

372 layers of polymerized fibrils in cross (upper) and oblique (lower) orientations

373 within the crystallized cocoon wall. Scale bar $50 \mathrm{~nm}$. 


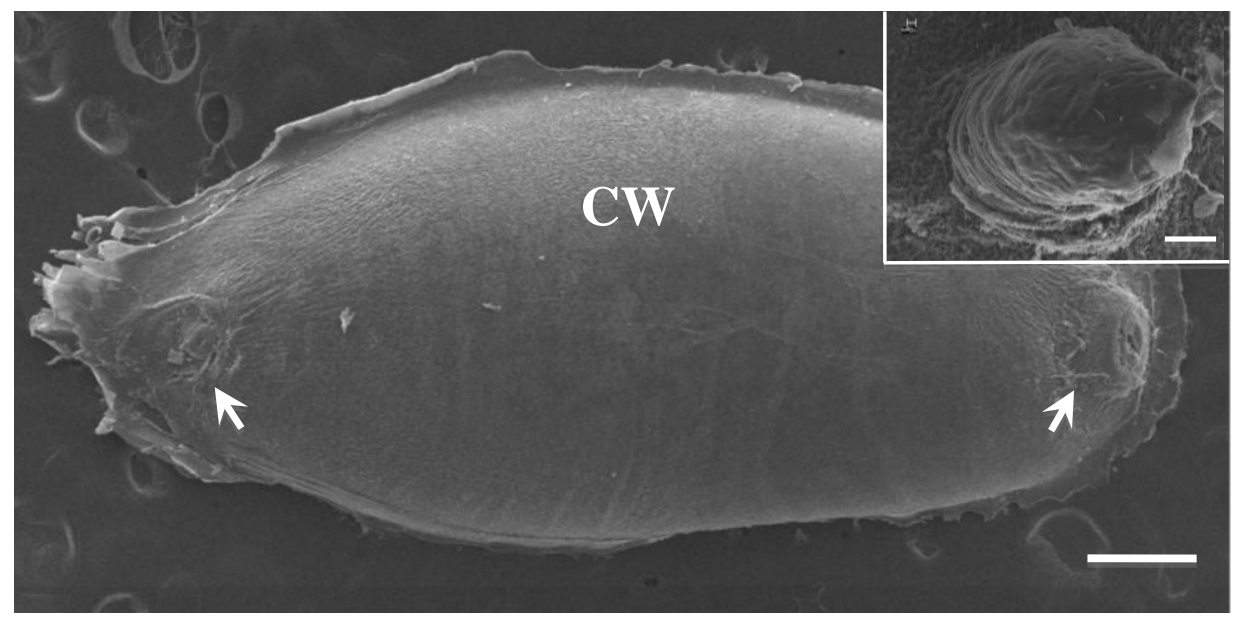

386

387

388

389

390

391 Figure 1. Fully assembled cocoon from the leech, Erpobdella obscura. The

392 cocoon wall (CW) forms a tube that is sealed at either end by opercula (arrows).

393 Scale bar $500 \mu \mathrm{m}$. Insert shows an outwardly protruding operculum. Scale bar $394100 \mu \mathrm{m}$.

395

396 

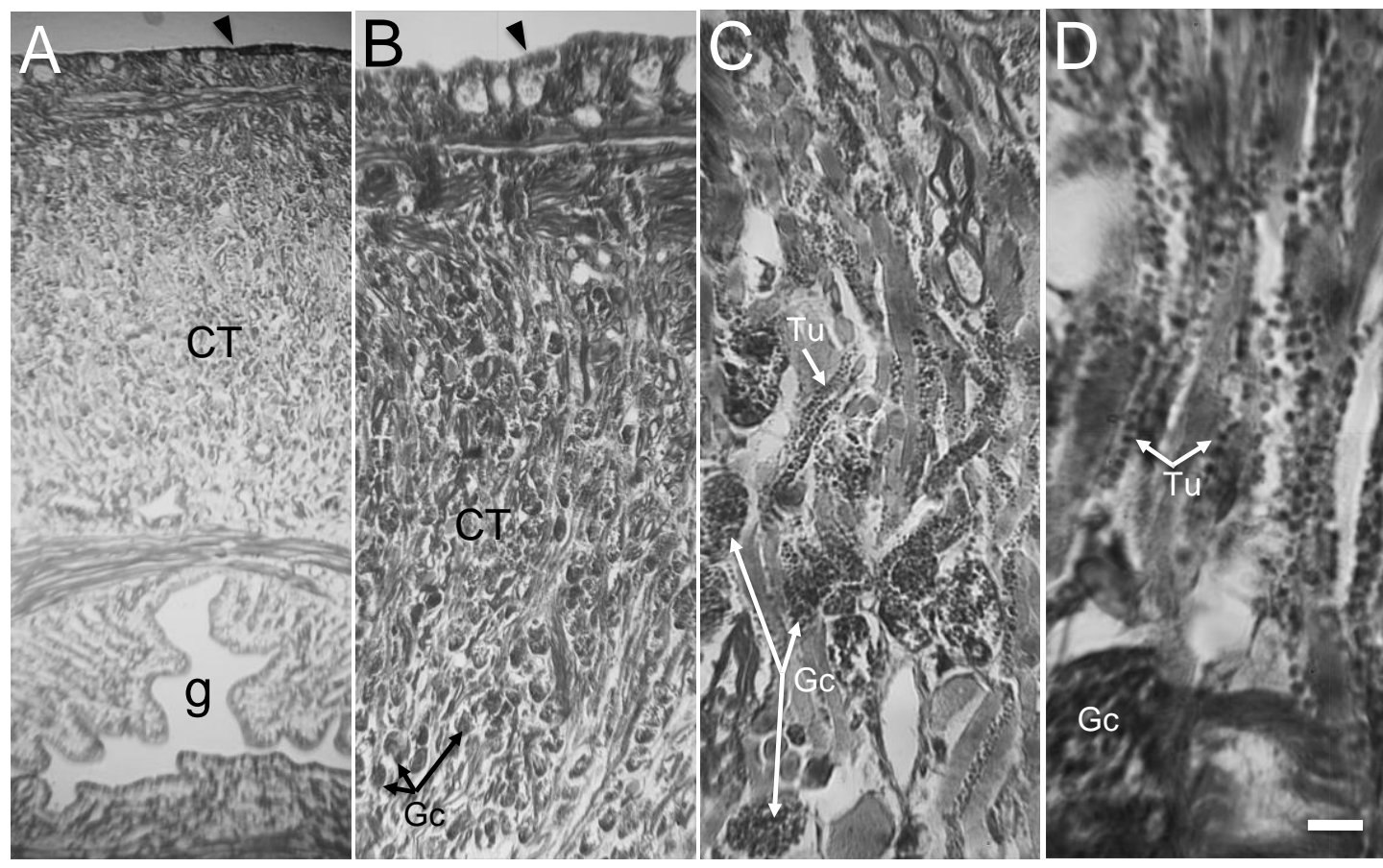

398

399

400 Figure 2. Histological cross-sections through the clitellum of an Erpobdella

401 obscura parent leech in the process of cocoon secretion. A) Clitellar tissue (CT)

402 containing secretory granule cells was observed between the gut $(\mathrm{g})$ and external

403 cuticle (arrowhead). Scale bar $100 \mu \mathrm{m}$. B) Granule cells (Gc) were abundant

404 within the CT. Scale bar $40 \mu \mathrm{m}$. C) Gc and tubules (Tu) were observed

405 throughout the CT. Scale bar $10 \mu \mathrm{m}$. D) Granules were apparent within Gc and

406 Tu. Scale bar $4 \mu \mathrm{m}$.

407 


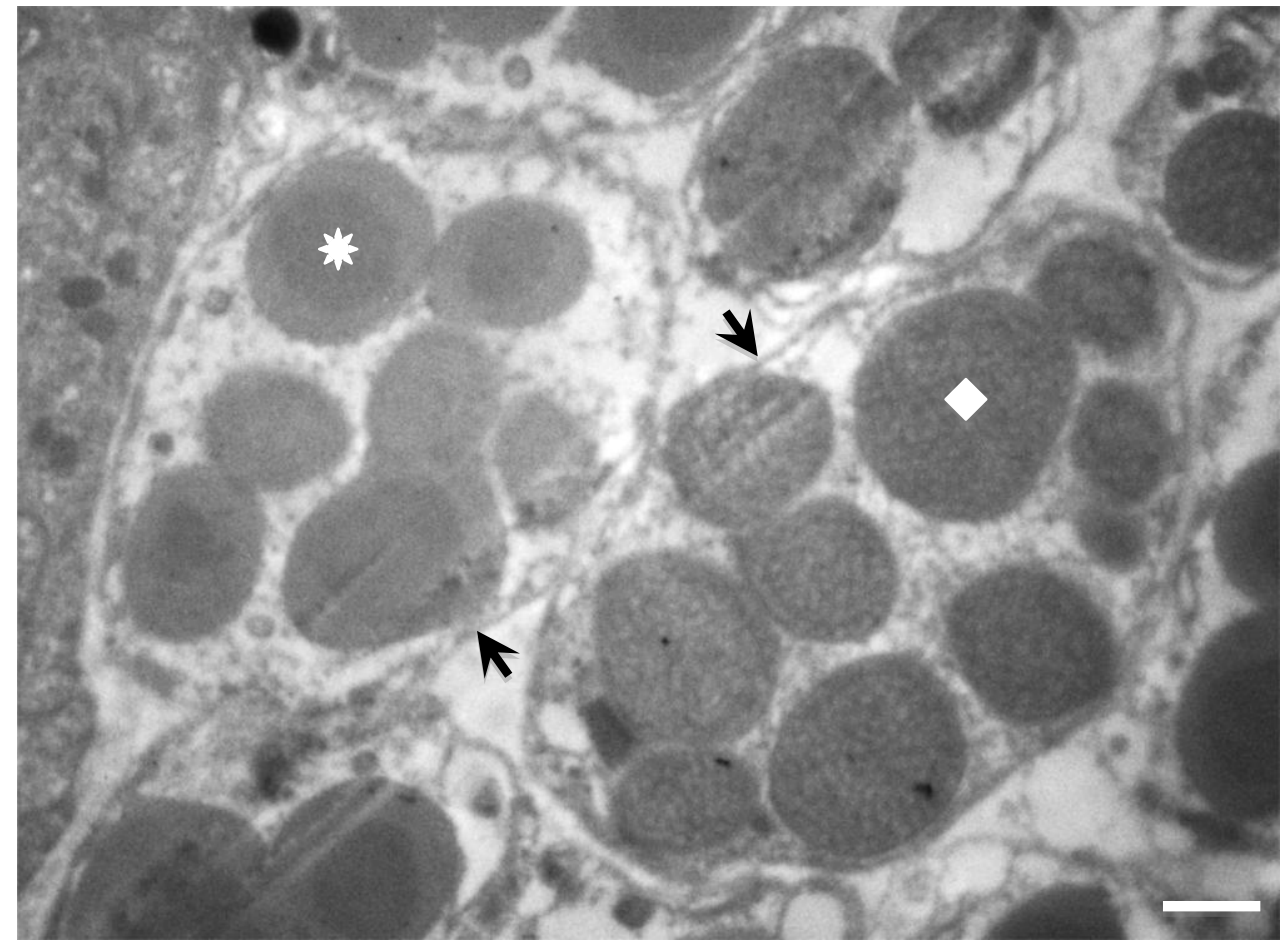

422

423

424

425

426

427 Figure 3. Granules within a clitellar secretory cell. Operculum-bound (star) and 428 cocoon wall-bound (diamond) granules were in sacs (arrows) containing 5-10 429 granules per sac. Scale bar $100 \mathrm{~nm}$.

430

431 

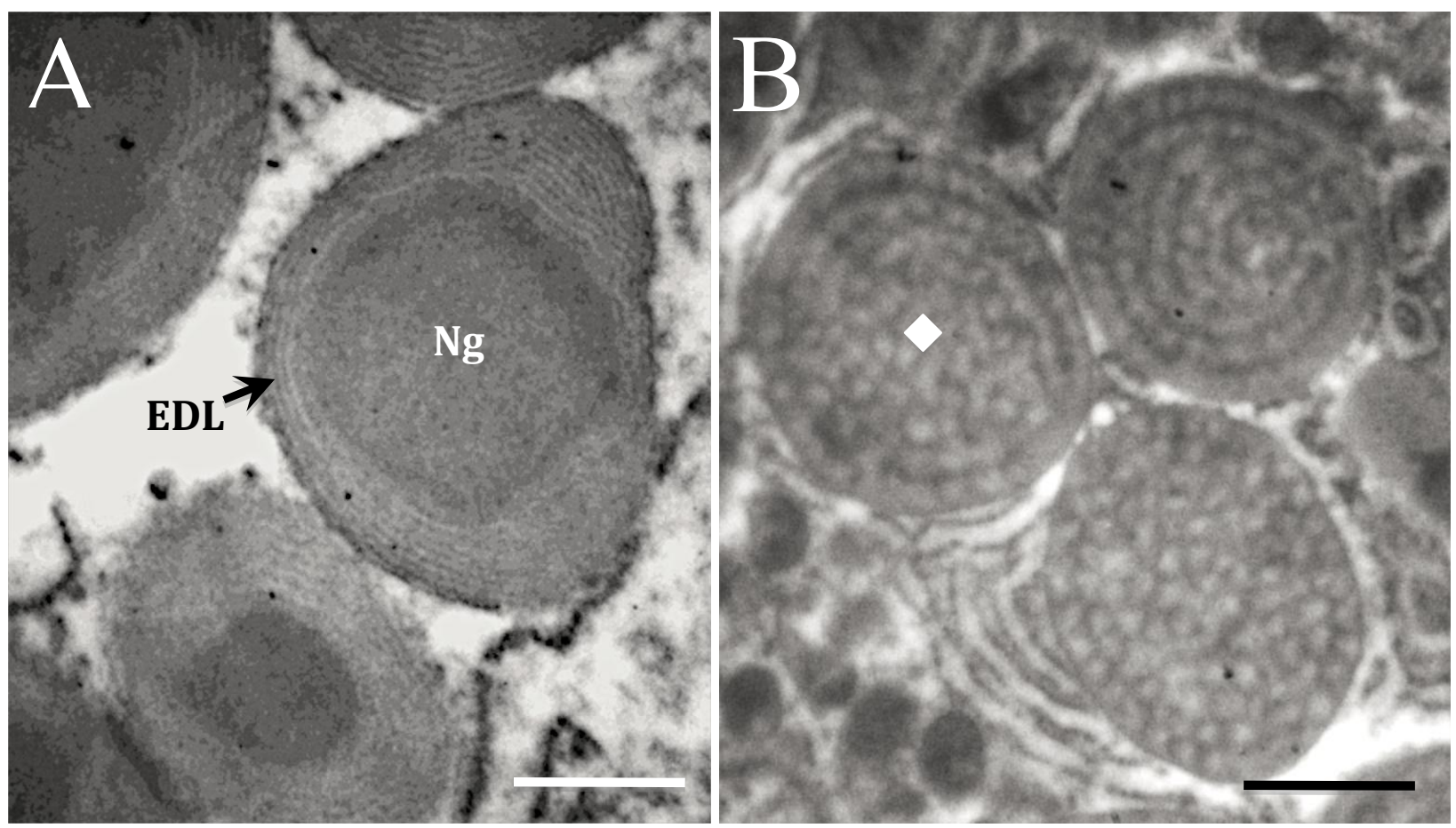

432

433

434

435

436

437

438

439

440 Figure 4. Distinct granule types within the clitellum of Erpobdella obscura. A)

441 Operculum-bound granules displayed electron dense lamellae (EDL) surrounding

442 a structureless core with dimensions comparable with mature nanoglobules $(\mathrm{Ng})$

443 found in opercula. B. Cocoon wall-bound granules (diamond) displayed

444 organized, punctate patterns. Scale bars $100 \mathrm{~nm}$.

445 
446

447

448

449

450

451

452

453

454

455

456

457

458

459

460

461

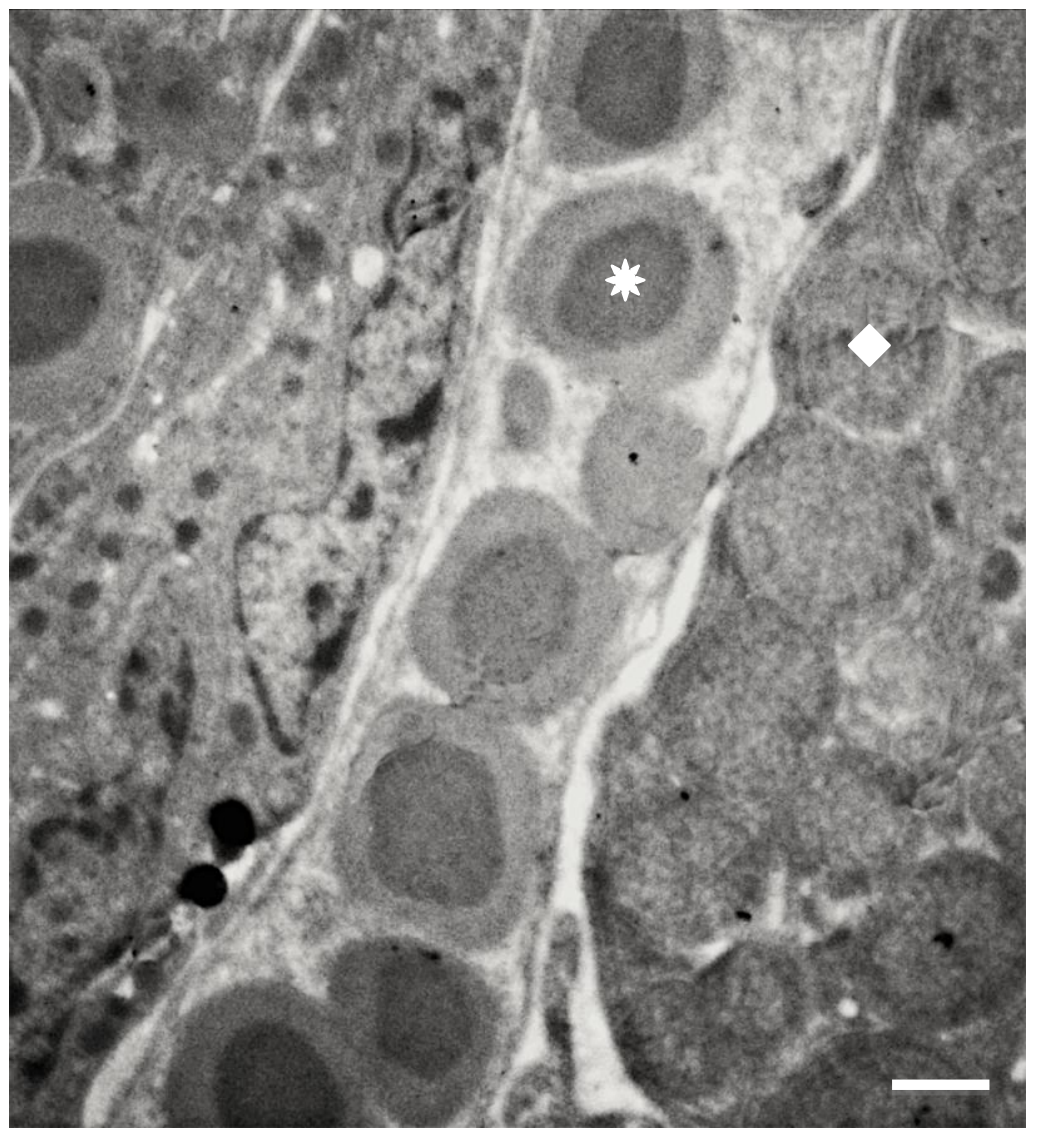

462

463

464

465

466

467

468

469 Figure 5. Operculum-bound granules (star) in a narrow tubule. Between 1-2

470 granules were channeled to the epidermal surface by tubules. Adjacent cocoon

471 wall-bound granules (diamond) are shown. Scale bar $100 \mathrm{~nm}$.

472 

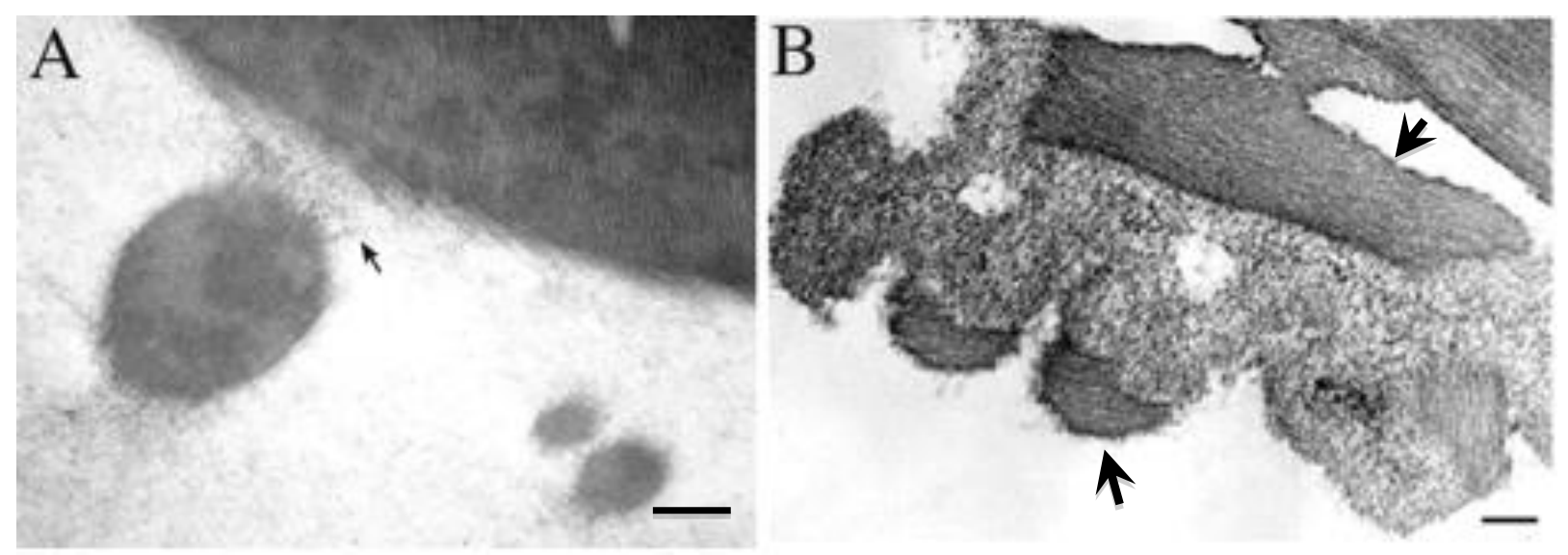

474

475

476

477

478

479

480

481

482 Figure 6. Interactions of granules with existing cocoon material in Theromyzon 483 tessulatum. A) Putative fusion of a granule with the cocoon wall, arrow identifies 484 the interface site. B) Regions of paracrystalization are adjacent to polymerized, 485 fibrous material (arrows). Scale bars $100 \mathrm{~nm}$.

486 


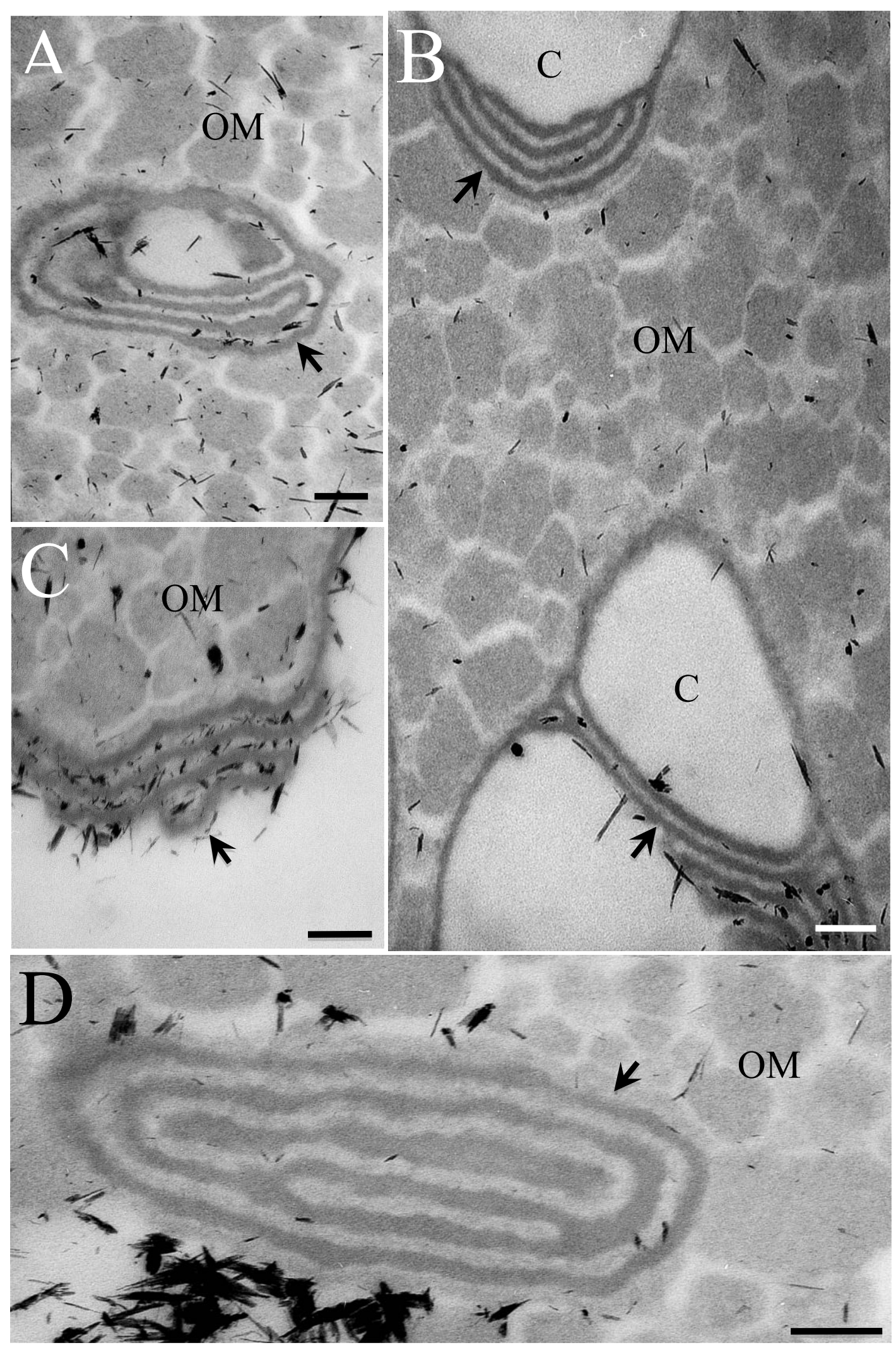

487

488 Figure 7. 

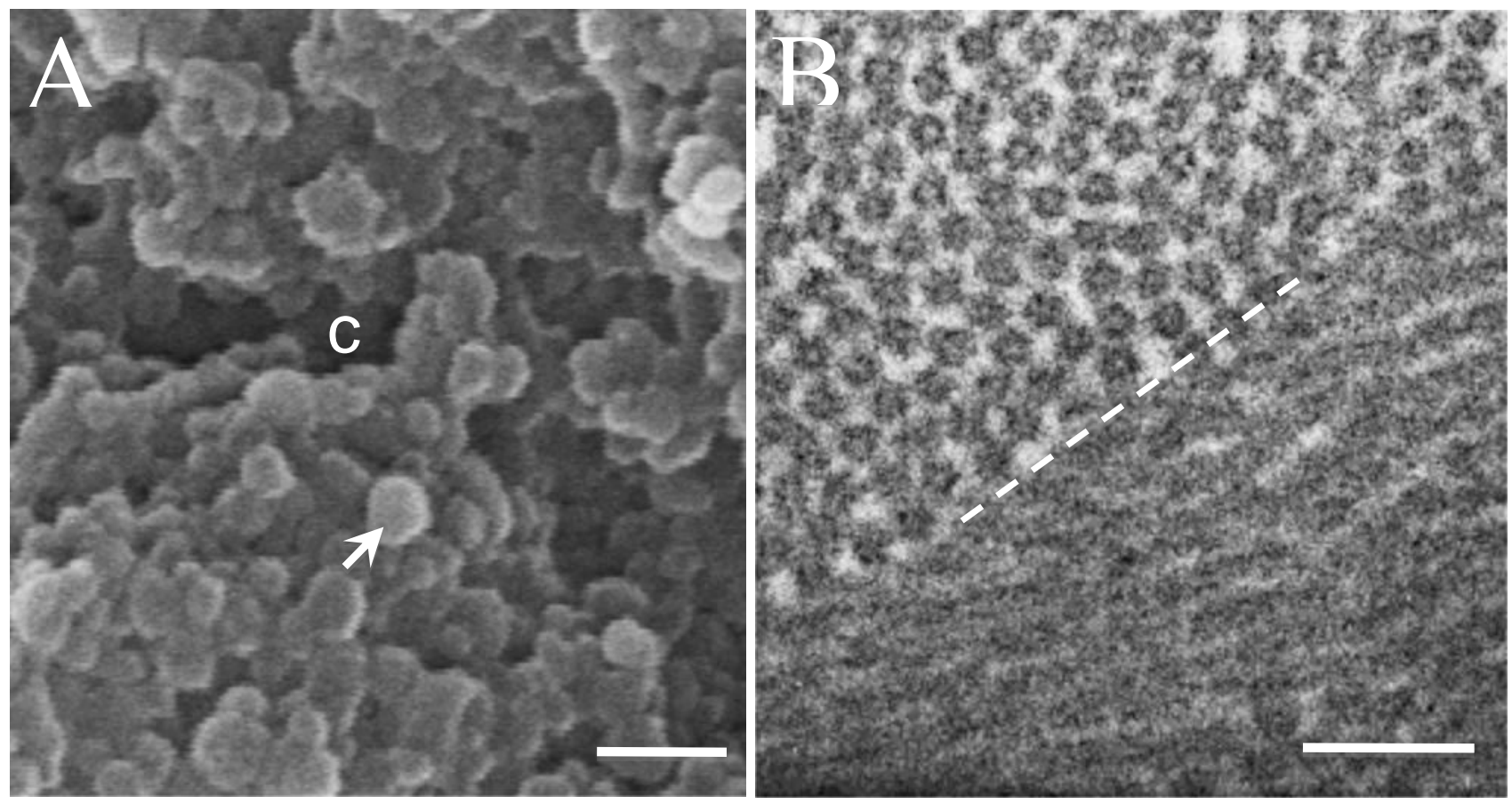

489

490

491

492

493

494

495

496

497

498

499

500

501

502

503

504

505 Figure 8. Ultrastructure of major Erpobdella obscura cocoon components. A)

506 Nanoglobules comprising operculum material. Arrow identifies a single

507 nanoglobule; c - cavity. Scale bar $500 \mathrm{~nm}$. B) Dashed line separates adjacent

508 layers of polymerized fibrils in cross (upper) and oblique (lower) orientations

509 within the crystallized cocoon wall. Scale bar $50 \mathrm{~nm}$. 